\title{
High-Shear De-Gassing and De-Ironing of an Aluminum Casting Alloy Made Directly from Aluminum End-of-Life Vehicle Scrap
}

\author{
Kawther Al-Helal ${ }^{1, *}$, Jaime Lazaro-Nebreda ${ }^{1}$, Jayesh B. Patel ${ }^{1}$ and Geoff M. Scamans ${ }^{2}$ \\ 1 Brunel Centre for Advanced Solidification Technology, Brunel University London, London UB8 3PH, UK;
jaime.lazaronebreda@brunel.ac.uk (J.L.-N.); jayesh.patel@brunel.ac.uk (J.B.P.)
2 Innoval Technology Limited, Beaumont Cl, Banbury OX16 1TQ, UK; geoff.scamans@innovaltec.com
* Correspondence: kawther.al-helal2@brunel.ac.uk
}

Citation: Al-Helal, K.;

Lazaro-Nebreda, J.; Patel, J.B.;

Scamans, G.M. High-Shear

De-Gassing and De-Ironing of an

Aluminum Casting Alloy Made

Directly from Aluminum

End-of-Life Vehicle Scrap. Recycling

2021, 6, 66. https://doi.org/10.3390/

recycling6040066

Academic Editor: Akira Otsuk

Received: 14 September 2021

Accepted: 7 October 2021

Published: 9 October 2021

Publisher's Note: MDPI stays neutral with regard to jurisdictional claims in published maps and institutional affiliations.

Copyright: (c) 2021 by the authors. Licensee MDPI, Basel, Switzerland. This article is an open access article distributed under the terms and conditions of the Creative Commons Attribution (CC BY) license (http://creativecommons.org/licenses /by/4.0/).
Abstract: High-shear melt conditioning (HSMC) technology was used for degassing and de-ironing of an aluminum alloy recovered from the Zorba cast fraction of the non-ferrous scrap from shredded end-of-life vehicles. The results showed that the recovery of aluminum alloys from the Zorba cast fraction was more than $80 \%$. High-shear melt conditioning improved the degassing process during melt treatment in comparison with the adding of degassing tablets. The efficiency of the de-ironing process using HSMC increased by up to $24 \%$ after, increasing the Mn content to $0.8 \%$ in the melt. Adding Mn to Zorba melt enhanced the de-ironing process and eliminated the formation of $\beta$-AlFeSi intermetallic particles, which have a detrimental effect on both the mechanical and corrosion properties of the alloy.

Keywords: recycled aluminum alloys; high-shear melt conditioning; degassing; de-ironing; Fe-rich intermetallic compounds

\section{Introduction}

End-of-life aluminum recycling plays an important role in low-carbon aluminum supply and can provided direct cost benefits in component manufacture compared to using primary aluminum. To overcome the recycling process challenges, it is essential to understand the industrial requirement to improve metals recycling efficiency [1]. Aluminum alloys are recyclable materials that can be extracted from end-of-life scrap components after many repeated cycles of casting and forming. Recycled aluminum can save natural resources, reduce energy consumption and the dependence of primary sources, and can reduce environmental pollution. Due to high demand of aluminum alloys, the challenge for recycling is to help to reduce $\mathrm{CO}_{2}$ emission in half by 2050 [2].

Zorba is the non-ferrous shredded mixed metal fraction of mainly aluminum scrap generated by shredding end-of-life vehicles mixed with white goods. In addition to aluminum alloys, Zorba contains nickel, copper, stainless steel, zinc, tin, magnesium, and lead. Once these "heavy" metals and magnesium have been removed the remaining aluminum fraction usually described as "Twitch" can then be roughly sorted into wrought and cast aluminum fractions using X-ray transmission technology (XRT). Depending on the source of the scrap fed into the shredder, the aluminum fraction may contain up to $60 \%$ of wrought fraction and can vary within the different size fractions with each grade requiring a different treatment procedure. Normally, the larger size fraction is the preferable one as it is easy for hand sorting or sorting using dense media separation. The smallest size fraction can now be processed using laser-induced breakdown spectroscopy (LIBS) which is a technology developed to separate the aluminum fraction more precisely into wrought and cast alloys by chemical analysis [3]. 
Because of the nature of the shredded scrap, when remelted, there tends to be an accumulation of oxides and other non-metallic inclusions. Most of these oxides float to the surface where they can easily be skimmed off, but a fraction normally remains trapped inside the melt, making it necessary to use further cleaning methods which are time consuming and require the use of fluxes that are not environment friendly [4]. Furthermore, it is very difficult to avoid completely the accumulation of undesired elements, such as iron. Due to the low solubility of iron in solid aluminum, a variety of intermetallic compounds (Fe-IMCs) form during solidification. The precipitation of these phases affects the surface quality of the products $[5,6]$ and their morphology and distribution have a significant impact on mechanical properties [7]. In particular, the formation of brittle phases and faceted large platelets of $\beta$-Als $\mathrm{FeSi}$ Fe-rich intermetallics causes a significant reduction in ductility and ultimate tensile strength of cast products. The current practice in industry for dealing with the accumulated iron in recycled melts is either diluting with primary aluminum, which is expensive, or downgrading the material to less demanding applications. Several techniques have been developed to remove iron, such as centrifuging, gravitational sedimentation, electromagnetic separation, filtration, electrolysis, fluxing, and electro slag refining [5]. The concept of iron removal in these methods is the precipitation of dense primary Fe-rich phases that form in the liquid at a temperature above the formation of the $\alpha$-Al phase. These primary phases form in many different morphologies depending on the $\mathrm{Mn} / \mathrm{Fe}$ ratio in the melt. When $\mathrm{Mn} / \mathrm{Fe}$ ratio is above 0.5 , the $\alpha-\mathrm{Al}_{15}(\mathrm{Fe}, \mathrm{Mn})_{3} \mathrm{Si}_{2}$ phase with compact shape is mostly formed, while for lower $\mathrm{Mn} / \mathrm{Fe}$ ratios, a combination of phases with different morphology can appear [5-8]. However, the formation of these primary Fe-IMCs is a slow process [9]. Morphological control of the Fe-IMCs and transformation from plate-like to compact shapes is therefore necessary to increase the removal efficiency and to reduce the negative impact on the final alloy quality and mechanical properties [10,11].

High-shear melt conditioning (HSMC) was developed at the Brunel Centre for Advanced Solidification Technology (BCAST) as a multi-purpose melt treatment technique [12]. The technology consists of a rotor-stator device [13] that provides both distributive mixing flow-like conventional impellers and also intensive dispersive mixing. It can be applied to casting processes, such as direct chill casting and twin roll casting [14]. It not only provides refinement and uniform distribution of the matrix and the Fe-rich phases [15], but also efficient degassing [16] and enhanced de-ironing [17], which has a significant effect on the reduction in microstructural defects and the improvement in tensile properties of the recycled aluminum alloy $[15,18]$.

This study has investigated the recycling efficiency and the impact of the high-shear melt conditioning (HSMC) process on the degassing and de-ironing of an aluminum alloy formulated from the cast aluminum fraction derived from a Zorba scrap stream.

\section{Experimental Procedures}

A cast fraction of $300 \mathrm{kgs}$ derived from X-ray transmission technology (XRT) (Axion Group, Manchester, UK) Sorted Twitch was received at BCAST for melt processing and composition analysis (Figure 1a). The scrap was melted at $720^{\circ} \mathrm{C}$ and cast into ingots for further treatment and characterization. Experiments were then conducted on these ingots to test the efficiency of high-shear melt conditioning for degassing and de-ironing of the cast fraction.

For degassing, two crucibles of $6 \mathrm{~kg}$ each were loaded with cast ingots and melted in electric resistance furnace at $720^{\circ} \mathrm{C}$. For the first crucible, $0.2 \mathrm{wt} . \%$ of degassing tablet (FOSECO Nitral C19) was added with manual stirring. The HSMC device and Argon gas pipe were immersed in the second crucible and degassing applied at an Argon flow rate of $0.1 \mathrm{l} / \mathrm{min}$ at a rotation speed of $3000 \mathrm{rpm}$ for $15 \mathrm{~min}$ [16]. The details of the HSMC device and assembly have been described in previous publication [12]. The reduced pressure test (RPT) [19] was used to evaluate the melt quality before and after the degassing process. For this test, $\sim 200 \mathrm{~g}$ of melt was poured into two conical steel cups and solidi- 
fied; one in ambient air and the other one under partial vacuum ( 80 mbar). The melt quality was then assessed by the density index (DI\%), which is obtained by Equation (1), where $D_{\text {air }}$ and $D_{\text {vac }}$ are the density of samples solidified in air and under vacuum, respectively.

$$
\mathrm{DI} \%=\left(\mathrm{D}_{\text {air }}-\mathrm{D}_{\mathrm{vac}}\right) / \mathrm{D}_{\text {air }} \times 100
$$

For de-ironing trials, the ingots were melted at $720{ }^{\circ} \mathrm{C}$ and sheared at $3000 \mathrm{rpm}$ speed for 15 minutes in a 6-kg batch process. The crucible was extracted from the processing furnace to allow the temperature to drop from $720{ }^{\circ} \mathrm{C}$ to below liquidus and then transferred to another furnace at a temperature between the liquidus and above the formation of the $\alpha$-Al phase to allow the formation and sedimentation of the primary iron intermetallics at constant temperature. After 30 minutes, the crucible was taken out from the furnace to let the melt solidify at room temperature. The temperature processing conditions were calculated using Pandat software [8]. To evaluate the effect of Mn additions on the removal of iron, parallel de-ironing trials were performed after alloying the ingot melt with Al-20Mn master alloy to raise the Mn content up to 0.8 wt. $\%$. HSMC was applied for 15 minutes at $720{ }^{\circ} \mathrm{C}$ and then followed the same procedure described before. For each experiment, samples were taken for chemical composition analysis to check the iron content before and after the melt treatment.

For microstructural analysis, samples were taken for all casting conditions by the standard TP1 test and mold preheated at $450{ }^{\circ} \mathrm{C}$, which corresponds to a cooling rate of $3.5 \mathrm{~K} / \mathrm{s}$ typical of commercial casting practices. The chemical composition for all samples was analyzed by optical emission spark spectrometry using a "Worldwide Analysis System (WAS) AG, Foundry master".

Metallographic characterization was carried out on samples taken from each casting process. The samples were mounted in Bakelite resin, ground, and then finally polished using a suspension of $0.04 \mu \mathrm{m}$ silica in water. All polished samples were anodized at 20 $\mathrm{V}$ for one minute in Barker's reagent to characterize the microstructure, porosity, and grain size. A Zeiss Axio-Vision optical microscope was used for analyzing the different casting conditions of the cast samples.

\section{Results and Discussion}

\subsection{Melting of the Zorba Cast Fraction Scrap in the As-Received Shredded Form}

Figure 1a shows photographs of the as-received cast fraction scrap, and Figure $1 \mathrm{~b}$ shows a selection of the aluminum alloy cast ingots and the dross collected after remelting. From the original $300 \mathrm{~kg}$ of cast fraction, $243 \mathrm{~kg}$ was cast as aluminum ingots and 57 $\mathrm{kg}$ was skimmed as dross. This result gave an $81 \%$ yield of aluminum alloy recovery from the cast fraction scrap. The chemical composition of the ingots is listed in Table 1. The composition of the cast ingots was very similar to commercial LM24 (UK) or LM27 (UK) alloys that make this material suitable for industrial applications after minimal composition adjustments. These cast fraction ingots were further refined by melt treatment by HSMC technology particularly for evaluating its effect on degassing and de-ironing of this $100 \%$ recycled content material. 

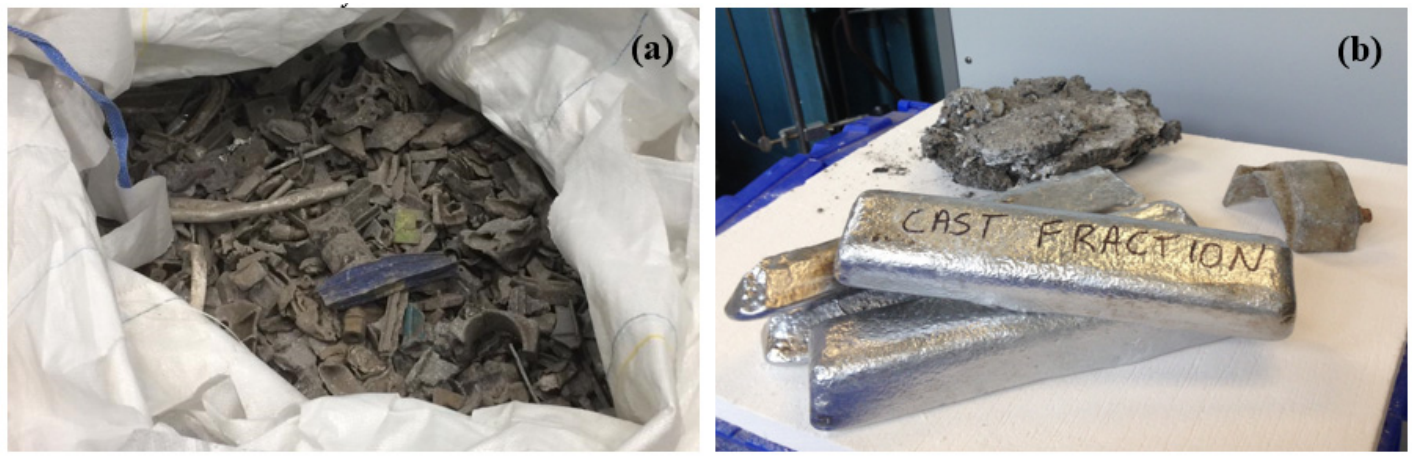

Figure 1. (a) As received Zorba cast fraction scrap in shredded form; (b) Aluminum alloy ingot and dross after remelting.

Table 1. Chemical composition of the aluminum alloy recovered from Zorba cast fraction compared with some typical commercial cast alloys.

\begin{tabular}{ccccccccccccc}
\hline Wt. $\%$ & $\mathbf{C u}$ & $\mathbf{M g}$ & $\mathbf{S i}$ & $\mathbf{F e}$ & $\mathbf{M n}$ & $\mathbf{N i}$ & $\mathbf{Z n}$ & $\mathbf{P b}$ & $\mathbf{S n}$ & $\mathbf{T i}$ & $\mathbf{C r}$ & $\mathbf{A l}$ \\
\hline Zorba Ingot & 2.34 & 0.55 & 6.32 & 0.80 & 0.21 & 0.08 & 0.89 & 0.07 & 0.03 & 0.06 & 0.03 & $\mathrm{Bal}$ \\
LM24 & $3.0-4.0$ & $<0.3$ & $7.5-9.5$ & $<1.3$ & $<0.5$ & $<0.5$ & $<3.0$ & $<0.3$ & $<0.2$ & $<0.2$ & - & $\mathrm{Bal}$. \\
LM27 & $1.5-2.5$ & $<0.35$ & $6.0-8.0$ & $0.5-0.7$ & $0.2-0.6$ & $<0.3$ & $<1.0$ & $<0.2$ & $<0.1$ & $<0.2$ & $<0.05$ & $\mathrm{Bal}$ \\
\hline
\end{tabular}

\subsection{De-Gassing by HSMC of the Zorba Cast Fraction Re-Melted Ingots}

The results from the RPT analysis are shown in Figure 2. The non-degassed melts showed a density index of $13.1 \%$, which decreased to $6.4 \%$ after the degassing tablet treatment and to $2.6 \%$ after HSMC degassing. This higher performance of the HSMC technology for degassing agrees with previous findings [16]. During HSMC with argon injection, all bubbles were captured and finely dispersed through the liquid metal into a large number of gas bubbles with a size much lower than $1 \mathrm{~mm}$ in diameter. This offers an increased surface area and residence time for the hydrogen diffusion from the melt in comparison with the tablet degassing method. HSMC also affects the entrapped oxide bi-films in the melt and transforms them into small and well dispersed particles which are much easier to attach to the generated bubbles and removed from the melt by flotation. In addition, the melt surface remains stable, with minimal disturbance and no vortex, which minimizes the re-absorption of hydrogen and creation of new oxide bi-films [16].
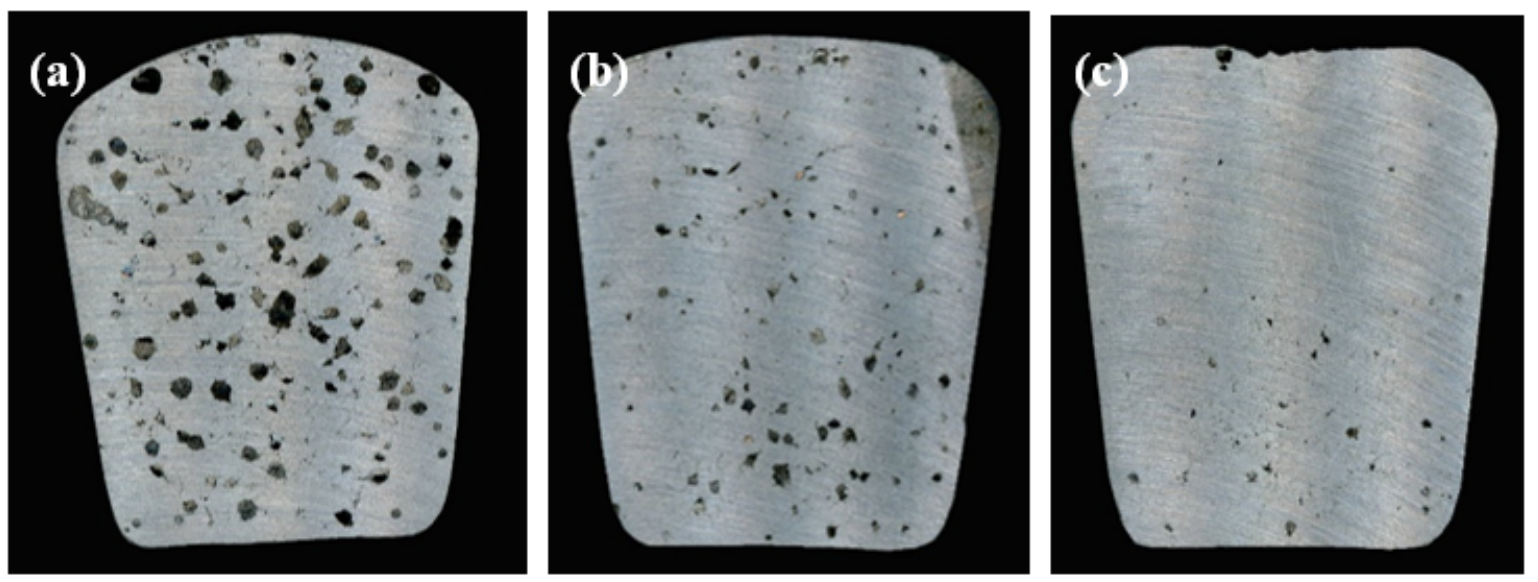

Figure 2. Porosity content for samples taken from Reduced Pressure Test (RPT) under partial vacuum; (a) without degassing; (b) with degassing tablet; and (c) degassed with high-shear melt conditioning. 
The improved melt quality had a direct effect on the microstructure and integrity of the castings. Figure 3 shows the microstructure and porosity content in the TP1 samples collected without degassing (Figure 3a), after degassing with a tablet (Figure 3b) and with high-shear melt conditioning (Figure 3c). Table 2 summarizes the microstructural analysis of samples shown in Figures 2 and 3 in terms of DI\%, porosity size, and fraction and grain size. The HSMC treatment enhanced refinement by reducing the grain size from $1750 \mu \mathrm{m}$ to $1160 \mu \mathrm{m}$ after HSMC, i.e., 33\% smaller. It also produced a decrease in the porosity fraction from $3.8 \%$ to only $0.5 \%$ when compared to the untreated material and the size of pores decreased from over $50 \mu \mathrm{m}$ to less than $20 \mu \mathrm{m}$ in size.
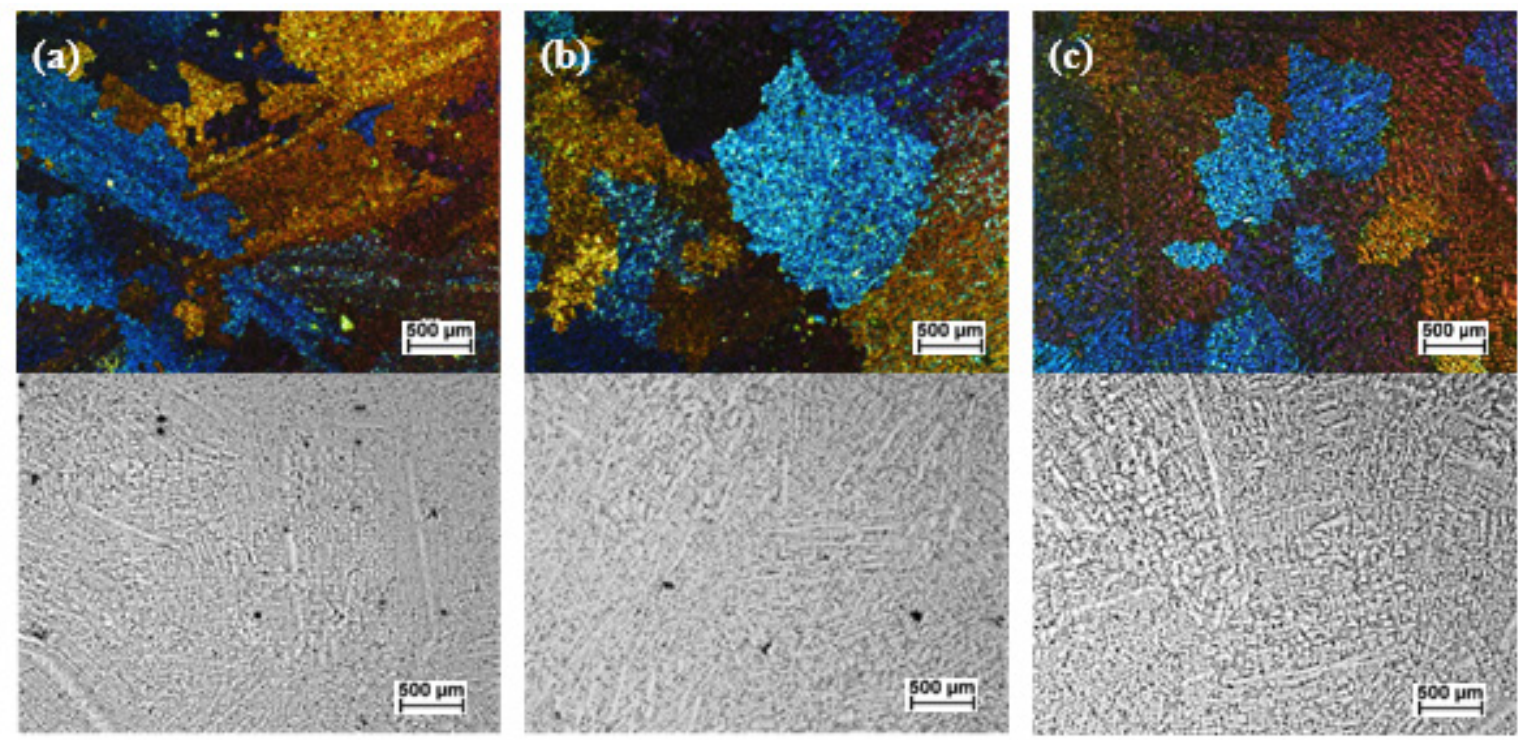

Figure 3. Optical micrographs of aluminum alloy recovered from Zorba Cast Fraction showing grain size (top) and porosity content (bottom) for: (a) without degassing; (b) degassing with tablet; and (c) degassed with high-shear melt conditioning.

Table 2. Microstructural features of TP1 samples before and after degassing of aluminum alloy recovered from the Zorba cast fraction.

\begin{tabular}{ccccc}
\hline Sample & $\begin{array}{c}\text { Density Index } \\
\text { DI\% }\end{array}$ & $\begin{array}{c}\text { Porosity Fraction } \\
\mathbf{( \% )}\end{array}$ & $\begin{array}{c}\text { Porosity Size } \\
(\mu \mathrm{m})\end{array}$ & $\begin{array}{c}\text { Grain Size } \\
(\mu \mathrm{m})\end{array}$ \\
\hline Before Degassing & 13.1 & 3.8 & $50 \pm 14$ & $1750 \pm 313$ \\
After Tablet Degassing & 6.4 & 1.8 & $35 \pm 14$ & $1560 \pm 235$ \\
After HSMC Degassing & 2.6 & 0.5 & $18 \pm 3$ & $1160 \pm 287$ \\
\hline
\end{tabular}

\subsection{De-Ironing by HSMC of the Zorba Cast Fraction Remelted Ingots}

\subsubsection{Effect of HSMC on the as Recovered Zorba Ingots}

Figure $4 \mathrm{a}$ shows the equilibrium phase diagram of the as-received alloy versus Fe wt.\%, calculated using Pandat software. A dashed vertical line was inserted to indicate the solidification sequence for the level of $0.8 \mathrm{wt} . \%$ Fe in the melt and the two horizontal dotted lines mark the temperatures of formation of the primary Fe-rich intermetallics and the formation of $\alpha$-Al.

Only $\mathrm{Al}_{15}(\mathrm{Fe}, \mathrm{Mn})_{3} \mathrm{Si}_{2}$ is expected to form in the range between $615^{\circ} \mathrm{C}$ and $607{ }^{\circ} \mathrm{C}$; this formation during solidification causes the liquid to become less concentrated in Fe and $\mathrm{Mn}$, as is shown in Figure $4 \mathrm{~b}$. The density of this primary intermetallic particle is about $3.2 \mathrm{~g} / \mathrm{cm}^{3}$, compared to density of the liquid aluminum of around $2.3 \mathrm{~g} / \mathrm{cm}^{3}[8]$, so they tend to sediment in the molten alloy when held between $607^{\circ} \mathrm{C}$ and $615^{\circ} \mathrm{C}$. At the holding temperature of $610{ }^{\circ} \mathrm{C}$, the liquid metal is expected to contain $0.17 \mathrm{wt} . \% \mathrm{Mn}$ and 0.77 wt. \% Fe. The experimental composition of cast aluminum alloy before and after the 
de-ironing process is listed in Table 3. This analysis showed that HSMC did not reduce the Fe and Mn content at this composition and under these processing conditions. This is because of the low $\mathrm{Fe}$ and $\mathrm{Mn}$ reduction which is expected $(0.03 \%$, within the error of the equipment), and the very small temperature processing window for the formation and sedimentation of the intermetallic phase. With only $8{ }^{\circ} \mathrm{C}$ difference between the formation of the $\alpha-\mathrm{Al}_{15}(\mathrm{Fe}, \mathrm{Mn})_{3} \mathrm{Si}_{2}$ and the formation of the $\alpha-\mathrm{Al}$, the chances of nucleation for the intermetallic phase become very low due to their high formation undercooling [9].

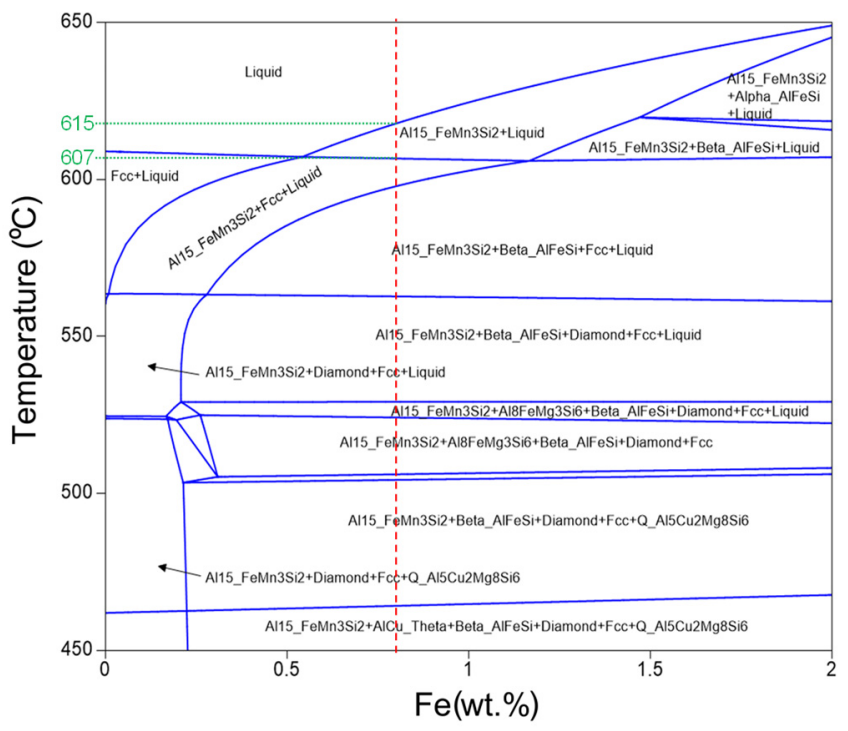

(a)

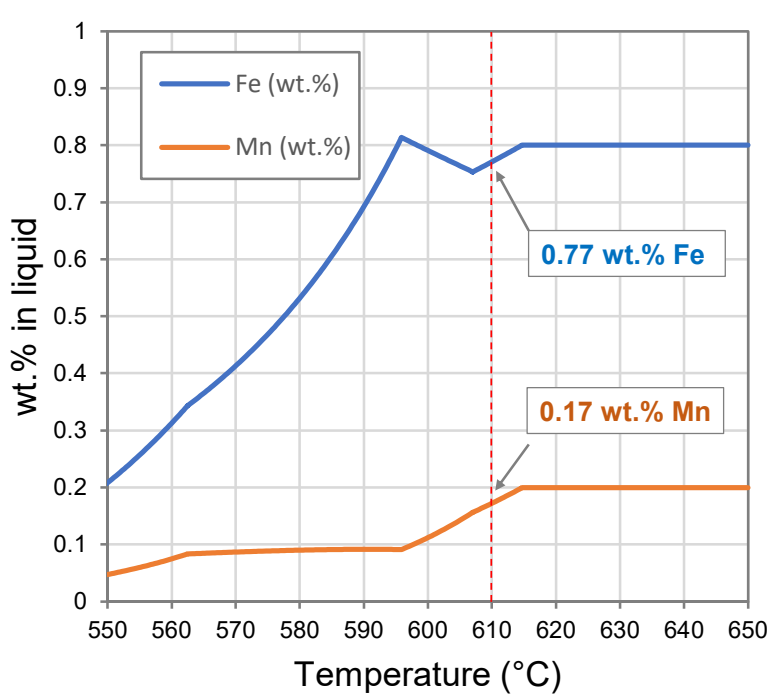

(b)

Figure 4. (a) Equilibrium phase diagram of the as-received Zorba cast fraction-xFe system, (b) Liquid composition of the as-received Zorba cast fraction alloy for the first trail.

Table 3. Chemical composition of the as-received Zorba cast fraction before and after de-ironing by high-shear melt conditioning.

\begin{tabular}{|c|c|c|c|c|c|c|c|c|c|c|c|c|}
\hline Wt. $\%$ & $\mathbf{C u}$ & Mg & Si & $\mathbf{F e}$ & Mn & $\mathbf{N i}$ & Zn & $\mathrm{Pb}$ & Sn & $\mathbf{T i}$ & $\mathrm{Cr}$ & Al \\
\hline Zorba Ingot & 2.34 & 0.55 & 6.32 & 0.80 & 0.21 & 0.08 & 0.89 & 0.07 & 0.03 & 0.06 & 0.03 & Bal. \\
\hline After HSMC and holding $30 \mathrm{~min}$ at $610^{\circ} \mathrm{C}$ & 2.32 & 0.57 & 6.36 & 0.81 & 0.22 & 0.08 & 0.86 & 0.07 & 0.06 & 0.06 & 0.05 & Bal. \\
\hline
\end{tabular}

Further solidification below $607^{\circ} \mathrm{C}$ showed the formation of other types of Fe-rich phases, such as $\beta$-AlFeSi in addition to the $\alpha$-AlFeMnSi phase. The $\alpha$-Al ${ }_{15}(\mathrm{Fe}, \mathrm{Mn})_{3} \mathrm{Si}_{2}$ intermetallics in cast Al-Mg-Si-Mn alloys have body-centered cubic structure and can appear in different morphologies, such as star-like, hexagonal, or dendritic crystal, depending on $\mathrm{Mn} / \mathrm{Fe}$ ratio. Compact shape is preferable to provide acceptable tensile properties of the final product $[20,21]$. The $\beta$-AlFeSi phase exhibits a plate-like morphology that can lead to local crack initiation and induces surface defects on the final cast material. The formation of irregular or large particles can result in high porosity due to the blocking of interdendritic flow region by these phases [11].

The microstructure of the aluminum alloy recovered from as-received cast ingots before and after de-ironing is shown in Figure 5. The micrographs show that there is no presence of the $\alpha-\mathrm{Al}_{15}(\mathrm{Fe}, \mathrm{Mn})_{3} \mathrm{Si}_{2}$ intermetallic, and only the $\beta$-AlFeSi phase was formed. This is an expected result since the undercooling for $\alpha$-Al ${ }_{15}(\mathrm{Fe}, \mathrm{Mn})_{3} \mathrm{Si}_{2}$ phase formation is higher, and, if formed, it would have shown some effect on the results presented in Table 3. The presence of the $\beta$-AlFeSi phase cannot be avoided by the de-ironing process, as they form together with the $\alpha$-Al and the higher viscosity retards their sedimentation. However, the use of HSMC shows a clear effect on the size of this 
$\beta$-AlFeSi plate-like phase decreased from $34( \pm 11) \mu \mathrm{m}$ in the reference material to $20( \pm 4)$ $\mu \mathrm{m}$ in the processed material, which agrees with previous studies [15].
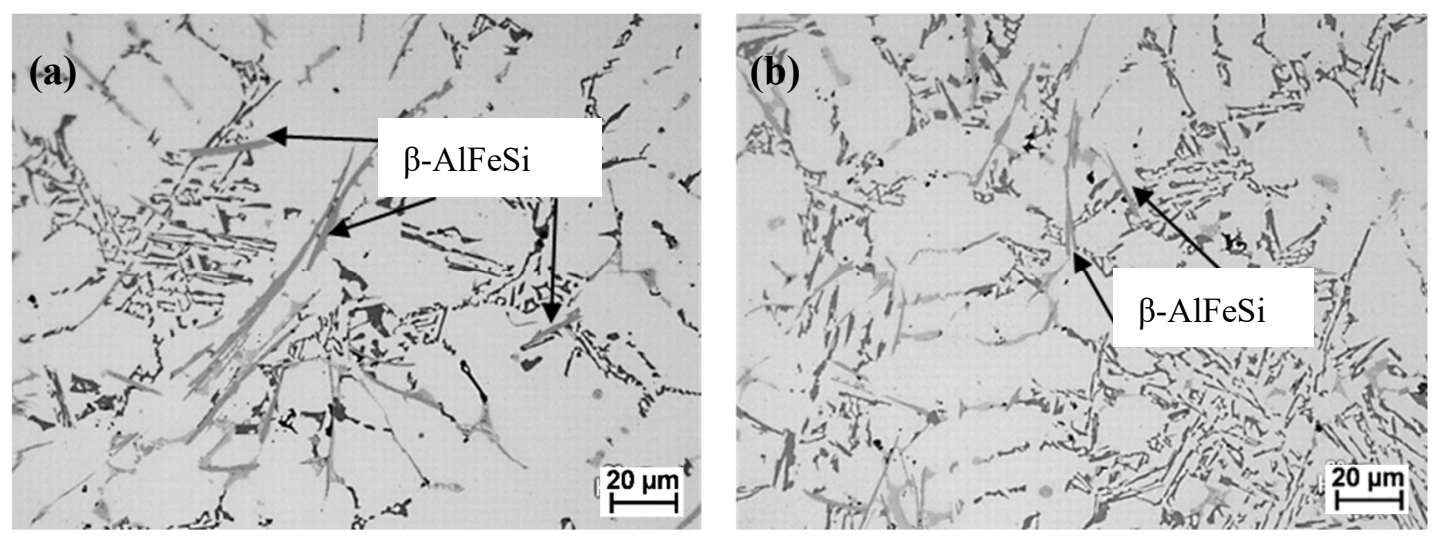

Figure 5. Optical micrographs of aluminum alloy formulated from as-received ingots; (a) before de-ironing, and (b) after HSMC de-ironing.

\subsubsection{Effect of HSMC on De-ironing after Mn Addition}

The addition of elements, such as $\mathrm{Mn}$ or $\mathrm{Cr}$, can promote the formation of large compact Fe-rich phases which increases the removal efficiency [8]. Figure 6a shows the equilibrium phase diagram of the ingot alloy versus Mn content. A dashed vertical line at $1 \% \mathrm{Mn}$ shows the content tested in this study. The only Fe intermetallic that forms before the formation of $\alpha-\mathrm{Al}$ is again the $\alpha-\mathrm{Al}_{15}(\mathrm{Fe}, \mathrm{Mn})_{3} \mathrm{Si}_{2}$ one; however in this case, the range is between $660{ }^{\circ} \mathrm{C}$ and $608{ }^{\circ} \mathrm{C}$. This wider temperature range enhances the potential for formation and sedimentation of this intermetallic compared to the as-received material (Figure 6a). Figure 6b shows the predicted weight percent of Fe and $\mathrm{Mn}$ in the liquid metal at different temperatures during the cooling process. At the holding temperature of $630{ }^{\circ} \mathrm{C}$, the liquid metal is expected to contain $0.58 \% \mathrm{Fe}$ and $0.45 \% \mathrm{Mn}$, which would match the LM24 or LM27 specifications (Table 1) and purify the material so that it is suitable for commercial use. However, the process has potential to further reduce the Fe and $\mathrm{Mn}$ content in the melt if held at a closer temperature to the $\alpha$-Al formation. For example, if held at $610{ }^{\circ} \mathrm{C}$, just above the $\alpha$-Al formation, a potential reduction to $0.46 \%$ Fe and $0.28 \% \mathrm{Mn}$ would be expected. The chemical composition of the modified alloy before and after HSMC processing and holding at $630{ }^{\circ} \mathrm{C}$ for 30 minutes are listed in Table 4 . This shows a decrease from $0.79 \%$ to $0.61 \%$ for Fe and from $0.78 \%$ to $0.56 \%$ for $\mathrm{Mn}$, which represents a relative reduction of $23 \%$ for Fe and $28 \%$ for $\mathrm{Mn}$.

Table 4. Chemical composition of modified Zorba cast fraction before and after de-ironing by high-shear melt conditioning.

\begin{tabular}{|c|c|c|c|c|c|c|c|c|c|c|c|c|}
\hline Wt. $\%$ & $\mathrm{Cu}$ & $\mathrm{Mg}$ & Si & Fe & Mn & $\mathrm{Ni}$ & Zn & $\mathbf{P b}$ & Sn & Ti & $\mathrm{Cr}$ & Al \\
\hline Zorba with Mn addition & 2.32 & 0.54 & 6.30 & 0.79 & 0.78 & 0.07 & 0.87 & 0.06 & 0.03 & 0.05 & 0.03 & Bal \\
\hline After HSMC and holding $30 \mathrm{~min}$ at $630^{\circ} \mathrm{C}$ & 2.41 & 0.57 & 6.28 & 0.61 & 0.56 & 0.08 & 0.90 & 0.07 & 0.04 & 0.06 & 0.05 & Bal \\
\hline
\end{tabular}




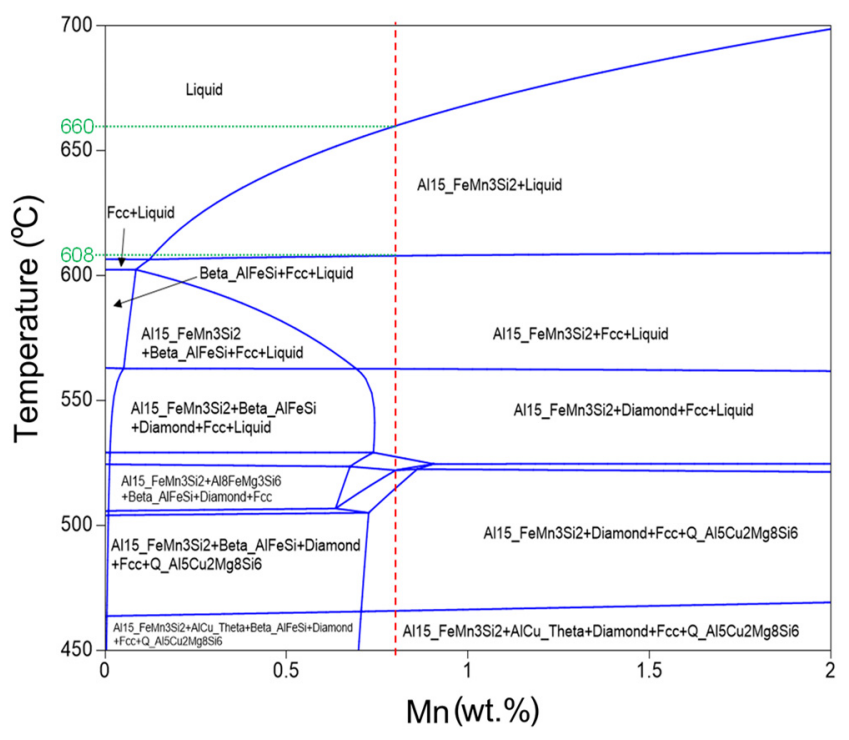

(a)

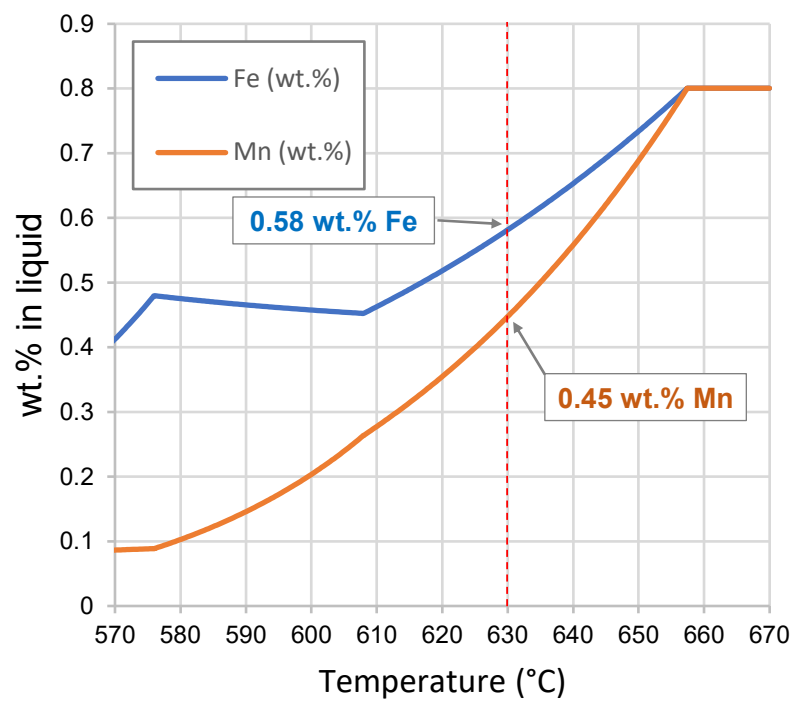

(b)

Figure 6. (a) Equilibrium phase diagram of the as-received Zorba cast fraction-xMn system, (b) Liquid composition of Zorba cast fraction alloy with the addition of $0.8 \mathrm{wt} . \% \mathrm{Mn}$ for the second trial.

The microstructure of the Mn-modified aluminum alloy recovered from the as-received ingots before and after de-ironing is shown in Figure 7. The micrographs show the presence of the compact $\alpha-\mathrm{Al}_{15}(\mathrm{Fe}, \mathrm{Mn})_{3} \mathrm{Si}_{2}$ intermetallic only. Adding $\mathrm{Mn}$ to the Zorba melt not only enhanced the de-ironing process, but also eliminated the formation of brittle plate-like $\beta$-AlFeSi intermetallic below the temperature when the $\alpha$-Al phase was formed, as presented in Figure 6a. This $\beta$-AlFeSi phase can be a weak point in coherence and a stress raiser; that is why it has a detrimental effect on mechanical and corrosion properties and its suppression has potential to improve the mechanical performance of the castings [6]. Furthermore, the application of HSMC in the de-ironing process provides a $\alpha-\mathrm{Al}_{15}(\mathrm{Fe}, \mathrm{Mn})_{3} \mathrm{Si}_{2}$ intermetallic size reduction from $107 \pm 37 \mu \mathrm{m}$ before to $72 \pm 14 \mu \mathrm{m}$ after the treatment.
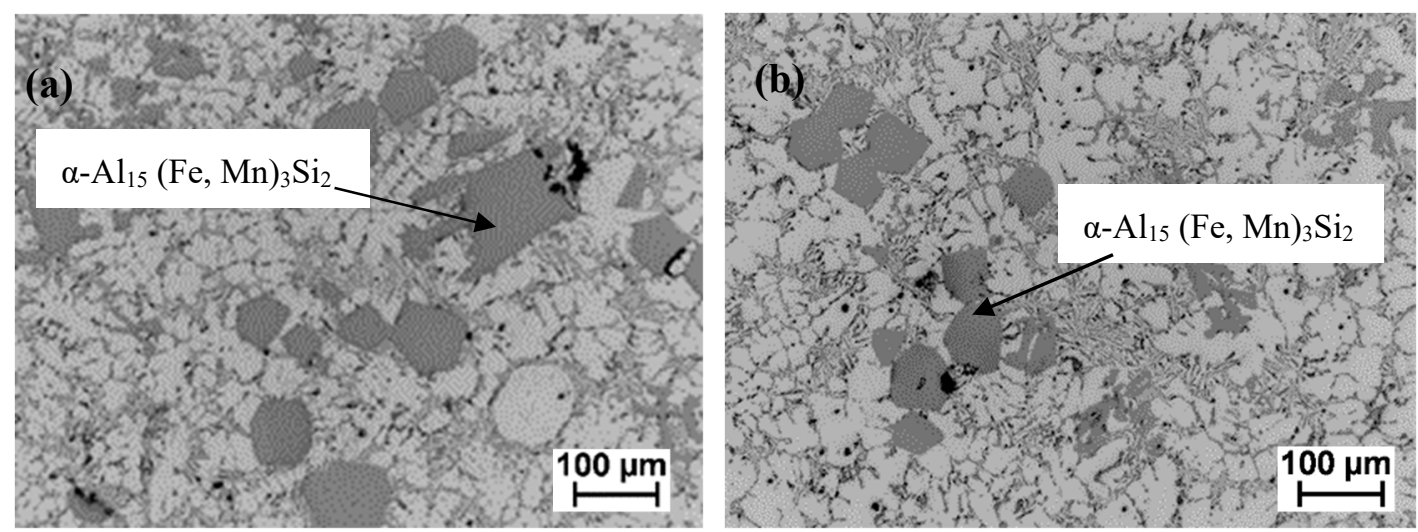

Figure 7. Optical micrographs of modified aluminum alloy recovered from the as-received Zorba cast fraction with $0.8 \%$ Mn; (a) before de-ironing, (b) after HSMC de-ironing.

\section{Conclusions}

High-shear melt conditioning (HSMC) technology was applied to the cleaning and purification of aluminum ingots recovered from twitch and processed by XRT sensing and sorting. It was found that: 
1. The recovery yield of the cast aluminum alloy was over $80 \%$.

2. Applying high-shear melt conditioning improved the degassing melt treatment in comparison with the traditional treatment of adding a degassing tablet. In addition, it provided grain refinement and reduced porosity content and size.

3. The technology provided refinement of the $\beta$-AlFeSi plate-like phase present in the high-Fe aluminum cast fraction scrap.

4. Adding $\mathrm{Mn}$ to the aluminum ingot melt enhanced the formation of the compact $\alpha-\mathrm{Al}_{15}(\mathrm{Fe}, \mathrm{Mn})_{3} \mathrm{Si}_{2}$ phase.

5. HSMC after a Mn addition provided enhanced formation of the compact intermetallics and an effective de-ironing process up to $23 \%$. It also helped the recovery of the added Mn with $28 \%$ effectiveness.

6. There is potential for further Fe and Mn removal from this scrap stream by adjusting the processing and holding temperature after HSMC.

7. The treated melt after the HSMC de-ironing process has a composition within the specifications of commercial alloys, such as LM24 and LM27, making it suitable for direct commercial use.

Author Contributions: K.A.-H. drafted the manuscript and performed the experiments with J.B.P. and J.L.-N.; K.A.-H., J.L.-N., J.B.P. and G.M.S. performed the data analyses; J.B.P. and G.M.S. revised the manuscript. All authors have read and agreed to the published version of the manuscript.

Funding: This research was funded by Innovate UK, grant number 102797 and the APC was funded by Brunel University London.

Acknowledgments: This work was carried out at Brunel Centre for Advanced Solidification Technology (BCAST), Brunel University London. Financial support from the REALITY Project No.102797 funding by Innovate UK and led by Jaguar Land Rover (JLR), is gratefully acknowledged.

Conflicts of Interest: The authors declare no conflict of interest.

\section{References}

1. Brooks, L.; Gaustad, G.; Gesting, A.; Mortvedt, T.; Freire, F. Ferrous and non-ferrous Recycling: Challenges and Potential Technology. Waste Manag. 2019, 85, 519.

2. Chang, I.; Luo, D.; Patel, J.B.; Al-Helal, K.; Huang, Y.; Scamans, G.; Fan, Z. Processing of Recycled AA6111 Aluminium Alloy from Two Different Feedstock of Aluminium Metal Scraps. J. Light Met. Weld. 2020, 58, $29-32$.

3. Available online: https://www.innovaltec.com/zorba-scrap-stream-blog/ (10 October 2021).

4. Zhang, L.; Lv, X.; Torgerson, A.T.; Long, M. Removal of impurity elements from molten aluminium: A review. Miner. Process. Extr. Metall. Rev. 2011, 31, 150-228.

5. Zhang, L.; Gao, J.; Damoah, L.N.W.; Robertson, D.G. Removal of iron from aluminium: A review. Miner. Process. Extr. Metall. Rev. 2012, 33, 99-157.

6. Mondolfo, L.F. Aluminum Alloys: Structure and Properties, 1st ed.; Butterworths: London, UK; Boston, MA, USA, 1976 ; p. 282.

7. Ji, S.; Yang, W.; Gao, F.; Watson, D.; Fan, Z. Effect of iron on the microstructure and mechanical property of Al-Mg-Si-Mn and Al-Mg-Si diecast alloys. Mater. Sci. Eng. A 2013, 564, 130-139.

8. Yang, W.; Gao, F.; Ji, S. Formation and sedimentation of Fe-rich intermetallics in Al-Si- Cu-Fe alloy. Trans. Nonferrous Met. Soc. China 2015, 25, 1704-1714.

9. Que, Z.; Wang, Y.; Fan, Z. Formation of the Fe-containing intermetallic compounds during solidification of Al-5Mg-2Si-0.7Mn-1.1Fe alloy. Mater. Metall. Trans. A 2018, 49, 2173-2181.

10. Ashtari, P.; Tezuka, H.; Sato, T. Modification of Fe-Containing Intermetallic Compounds by K Addition to Fe-Rich AA319 Aluminum Alloys. Scr. Mater. 2005, 53, 937-942.

11. Mbuya, T.O.; Odera, B.O.; Ng'ang'a, S.P. Influence of iron on castability and properties of aluminium silicon alloys: Literature review. Int. J. Cast Met. Res. 2003, 16, 451-465.

12. Lazaro-Nebreda, J.; Patel, J.B.; Scamans, G.M.; Fan, Z. Multi-Purpose High Shear Melt Conditioning Technology for Effective Melt Quality and for Recycling of Al-Alloy Scrap. In Proceedings of the 16th International Aluminium Alloys Conference (ICAA16); Canadian Institute of Mining, Metallurgy \& Petroleum: Canada, 2018; p. 401623.

13. Fan, Z.; Zuo, Y.B.; Jiang, B. Apparatus and Method for Liquid Metals Treatment. WO-2012035357-A1, 2012.

14. Patel, J.B.; Li, H.T.; Xia, M.X.; Jones, S.; Kumar, S.; O’Reilly, K.; Fan, Z. Melt Conditioned Direct Chill Casting (MC-DC) Process for Production of High Quality Aluminium Alloy Billets. Mater. Sci. Forum. 2014, 794, 149-154. 
15. Al-Helal, K.; Patel, J.B.; Fan, Z. Fe-Rich Intermetallic Formation and Mechanical Properties of Recycled AA6111 Alloy Strips Produced by Melt Conditioning Twin Roll Casting. JOM 2020, 72, 3753-3759.

16. Lazaro-Nebreda, J.; Patel, J.B.; Fan, Z. Improved degassing efficiency and mechanical properties of A356 aluminium alloy castings by high shear melt conditioning (HSMC) technology. J. Mater. Process. Technol. 2021, 294, 117146-117157.

17. Lazaro-Nebreda, J.; Patel, J.B.; Chang, I.T.H.; Stone, I.C.; Fan, Z. Solidification processing of scrap Al-alloys containing high levels of Fe. IOP Conf. Ser. Mater. Sci. Eng. 2019, 529, 012059-012065.

18. Zhang, Y.; Patel, J.B.; Lazaro-Nebreda, J.; Fan, Z. Improved Defect Control and Mechanical Property Variation in High-Pressure Die Casting of A380 Alloy by High Shear Melt Conditioning. JOM 2018, 70, 2726-2730.

19. Dispinar, D.; Campbell, J. Critical assessment of reduced pressure test. Part 1: Porosity phenomena. Int. J. Cast Met. Res. 2004, 17, 280-286.

20. Al-Helal, K.; Lazaro-Nebreda, J.; Patel, J.B.; Scamans, G.M.; Fan, Z. Melt Conditioned Direct Chill (MC-DC) Casting of AA-6111 Aluminium Alloy Formulated from Incinerator Bottom Ash (IBA). Recycling 2019, 4, 37-46.

21. Snopinski, P.; Krol, M.; Tanski, T.; Krupinska, B. Effect of cooling rate on microstructural development in alloy ALMG9. J. Therm. Anal. Calorim. 2018, 133, 379-390. 